\title{
The translation of reporting verbs in Italian
} The case of the Harry Potter series

\author{
Lorenzo Mastropierro
}

University of Nottingham

This paper reports on a study of reporting verbs in the Harry Potter series and their translation in Italian. It offers quantitative and qualitative perspectives on how the English verbs have been translated by two Italian translators, who worked on different books of the series. This study first analyses verb usage across the three protagonists of the series (Harry, Ron, and Hermione) in English and Italian; then, it employs Caldas-Coulthard's (1987) taxonomy of reporting verbs and compares verb categories between source and target texts to identify tendencies in the translation of this textual feature. It finally discusses the stylistic implications of translation alterations and their potential effect on character development. As such, this paper contributes not only to the limited literature on reporting verbs in translation (especially in Italian), but it also furthers the understanding of the role of reporting verbs as a characterisation device.

Keywords: reporting verbs, literary translation, stylistics, corpus-based translation studies, Harry Potter series

\section{Introduction}

Characterisation has been defined as the process through which "we form impressions of characters in our minds" as we read (Culpeper, 2001:2). This process is the result of the interaction between the reader's schematic knowledge and textual cues (Culpeper, 2001), which could be explicit and implicit. Implicit characterisation is often triggered by character speech: as Simpson (2004:21) explains, the development of a character accounts for how processes of "saying" are attributed to them. How characters say what they say, then, is an essential aspect of their representation in the text, and reporting verbs contribute importantly to conveying this aspect. This paper explores how such a significant characterisation device is translated in Italian, through a comparison of reporting verbs in J. K. Rowling's

Appendices available from https://doi.org/10.1075/ijcl.19124.mas.additional https://doi.org/10.1075/ijcl.19124.mas

International Journal of Corpus Linguistics 25:3 (2020), pp. 241-269. issn 1384-6655|e-issn 1569-9811

2 Available under the CC BY-NC 4.0 license. (c) John Benjamins Publishing Company 
Harry Potter book series and its Italian translation. In particular, reporting verbs attributed to the three protagonists of the series - Harry, Ron, and Hermione - in the source texts (STs) are compared to their translation in the Italian target texts (TTs), both in terms of number of tokens and types and in terms of verb category, following Caldas-Coulthard's (1987) taxonomy of reporting verbs. This twofold comparison not only allows me to identify quantitative differences in the variety of verbs used between STs and TTs, but also to define qualitatively the nature of the translation alterations with regards to verb category. These shifts are then discussed in terms of potential effects they can produce on character development, in particular on that of Harry.

This paper is organised as follows. Section 2 introduces reporting verbs and their study, especially in relation to their role as a characterisation device. It also offers an overview of the existing literature on the translation of reporting verbs. Section 3 presents the data and methods of this study, explaining how reporting verbs are retrieved and categorised. A comparison of reporting verbs in the STs and TTs is presented in Section 4, while Section 5 expands on the findings of the previous section by comparing verb categories. Particular attention is paid to the identification of tendencies and patterns in the shift from the source to the TTs. Section 6 offers two brief case studies that discuss the potential stylistic effects of the translation alterations and tendencies identified in Sections 4 and 5, focusing on the development of Harry as a character throughout the series. Section 7 provides the paper's conclusion.

\section{Reporting verbs and their translation}

Reported speech is a key element in many written texts, both fictional and nonfictional (see Caldas-Coulthard, 1994; Semino \& Short, 2004). When speech is reported directly, through a mode of presentation commonly known as 'direct speech' (Leech \& Short, 2007: 255), it is usually followed or preceded by a reporting verb, as shown in Examples (1) and (2):

(1) “What's happened?" Harry said. [Harry Potter and the Order of the Phoenix]

(2) “Harry, what's happened?" bellowed Hagrid.

[Harry Potter and the Deathly Hallows]

Reporting verbs have several functions, from simply attributing the reported speech to a speaker to glossing the discourse being quoted and providing interpretative value beyond the words uttered. The reported element in Examples (1) and (2) is the same (what's happened?), but the reader is likely to interpret it having a 
very different prosodic and expressive charge because of the different verb used to gloss the quotation, said and bellowed. Reporting verbs do not only affect the meaning of the reported speech, they also contribute to the reader's perception of the speaker. Culpeper (2001: 215) explains that the way characters speak can trigger information about their personality type, as character traits are reflected and projected by the verbs used to report speech (Ruano San Segundo, 2016:114). It is not surprising, then, that reporting verbs are considered an important characterisation device in literary texts.

Ruano San Segundo (2016, 2017b) has extensively demonstrated the characterising potential of reporting verbs, especially in Dickens's novels. He shows, for example, that some verbs are used with certain characters only, representing a highly distinctive and defining feature of a character. This is the case of Pancks, in Little Dorrit, the only character in the whole of Dickens's oeuvre for which the reporting verb snorted is used (Ruano San Segundo, 2016:126). For major characters, the sum of a more varied set of verbs emphasises their role, as in the case of Ralph Nickleby (in Nicholas Nickleby), whose villainous nature is accentuated by the use of verbs such as demanded and interrupted (Ruano San Segundo, 2017b). Reporting verbs can also project animalistic and wild undertones to characters associated with verbs like roared, bawled, and growled (Ruano San Segundo, 2018b), or they can be used to distinguish male and female characters by conveying gendered characterisation. This is shown by Eberhardt (2017) and Ruano San Segundo (2018a), who explore the relationship between reporting verbs and gender in the Harry Potter series and in Dickens's novels, respectively. Their findings align inasmuch as both studies identify patterns of reporting verbs that contribute to a dichotomous characterisation of male and female characters, reflective of stereotypical gender views. For instance, while male characters bellow and growl, female ones sob and shriek (Eberhardt, 2017: 235; Ruano San Segundo, 2018a: 202).

The stylistic significance of reporting verbs makes them an important concern in literary translation. The reproduction of reporting verbs in translation is essential in order to replicate the characterising traits they endow to the characters associated with them. Conversely, an alteration of the patterns of reporting verbs can lead to a different representation of the speaker in the translated text. Yu \& Guo (2016) show how the portrayal of Huineng, a Chan Buddhism master in the Platform Sutra, is altered by the choice of reporting verbs used to gloss speech in his sermons. They compare four English versions of the sutra, discussing how the verb choices of two translators contribute to portray Huineng as "kind and intimate" (reply, exclaim, commend, reprove), while the verbs used by the other two (demand, pronounce, impart) present Huineng as "superior and authoritative" (Yu \& Guo, 2016:276). Similarly, Čermáková \& Mahlberg (2018) discuss reporting 
verbs as a characterisation device in Lewis Carroll's Alice's Adventures in Wonderland and one of its Czech translations. They focus on verbs attributed to Alice and the Queen, identifying patterns of usage that are character-specific: "while 'loud' verbs, such as screamed and shouted, are typical of the Queen, with Alice we find inner speech (the phrase to herself occurs exclusively with Alice)" (Čermáková \& Mahlberg, 2018:248). The lack of consistency in the Czech translation of reporting verbs, together with a tendency to avoid the repetition of said and replace it with a wider selection of different verbs, alter the ST reporting verb patterns. As a result, the characterising potential of these patterns can be affected in translation. Finally, Ruano San Segundo (2017a) investigates the translation of reporting verbs in four Spanish versions of Dickens's Hard Times. His analysis concentrates on individual examples (as opposed to the identification of general patterns in the TTs) in order to demonstrate how each individual divergence from the ST verb has the potential to affect characterisation. These studies evidence the importance of investigating the translation of reporting verbs, so as to emphasise the major effect that translating could have on "what most powerfully attracts readers to novels and stories" (Toolan, 2001:80) - characters.

While the literature on the translation of reporting verbs is limited, the existing studies share one important finding: there seems to be a tendency for English reporting verbs to be translated with a wider variety of target language reporting verbs. Rojo \& Valenzuela (2001), who study reporting verbs in four English novels and their Spanish translations, find that the TTs use a larger range of verb types compared to the STs: "Spanish translators used sixty different Spanish verbs to translate the fifty verbs used in the English novels" (Rojo \& Valenzuela, 2001: 470). Moreover, Rojo \& Valenzuela (2001) distinguish reporting verbs in two categories: "general", such as say or tell, and "specific", such as growl or murmur. Investigating the strategies used to translate each verb category, Rojo \& Valenzuela (2001:472) show that, when an English reporting verb is translated with a Spanish verb of a different category, it is most frequently a general verb turned into a specific verb, rather than the other way round. They explain that "Spanish translators tended to add information, using more specific verbs" (Rojo \& Valenzuela, 2001:375). Similarly, Bourne (2002) looks at the translation of reporting verbs in Spanish, and he, too, finds a greater variety of different verbs in the translation of 100 reporting verbs from Joanna Trollope's novel The Men and the Girls. In particular, it is the verb said that presents the largest variability in its Spanish translation: the dictionary equivalent decir ("to say") is used only 17 out of 56 times, while different verbs are used in 35 occasions (plus four omissions) (Bourne, 2002: 246-247). A similar result is obtained by Corness (2010), who specifically explores the Czech translation of the verb said in 22 English novels. He finds that, out of 9,992 occurrences of said in English, only $33 \%$ are translated with equivalent neutral verbs 
in Czech, while in $56.6 \%$ of the cases a translation shift occurs, often involving the use of a more semantically specific verb (Corness, 2010:163-164). Klaudy \& Károly (2005) investigate the translation of 100 reporting verbs for each of three novels and their translation: one English novel and its Hungarian translation and two Hungarian novels and their English translations. They, too, find that the 100 English verbs are translated with a larger number of verb types in Hungarian (14 vs. 32); however, the opposite is not true. The 100 verbs each from the two Hungarian novels are translated with the same or a fewer number of verb types in English (56 vs. 56 and 27 vs. 24). This twofold result is also reflected in the number of reporting verbs occurring only once: translating from English into Hungarian, the number of reporting verbs occurring once increases, while from Hungarian to English the number decreases (Klaudy \& Károly, 2005: 21). Finally, Winters (2007) investigates the translation of the 19 most frequent reporting verbs in $\mathrm{F}$. Scott Fitzgerald's The Beautiful and Damned in two different German versions. She notes that both translators use a wider range of verb types to render the English verbs: 59 and 128 different German verbs (Winters, 2007: 416).

Given the limited number of studies on the topic, it is difficult to interpret this shared finding conclusively, but several hypotheses could be formulated. The tendency to translate English reporting verbs with a greater variety of target language verbs seen in Rojo \& Valenzuela (2001), Bourne (2002), Klaudy \& Károly (2005), Winters (2007), and Corness (2010) can be considered as an instantiation of the explicitation translation universal (Baker, 1993; Øverås, 1998; Laviosa, 2002; Blum-Kulka, 2004), according to which TTs are characterised by a "marked rise in the level of explicitness" compared to STs (Baker, 1993:243). In the case of reporting verbs, this would mean translating (some instances of) general reporting verbs such as said and told with more explicit ones, such as whispered and shouted, increasing in this way the number of different verb types in the TT. However, more data from a larger set of language pairs is needed to be able to talk about a universal feature, not counting the fact that Klaudy \& Károly (2005) show that the opposite of explicitation, implicitation, occurs when the translation direction is inverted from English to Hungarian to Hungarian to English. This raises questions about the universality of this tendency. A less generalisable explanation could be found in the difference in narrative style between these languages, which is then reflected in the use of reporting verbs. Rojo \& Valenzuela (2001:476) explain that, even though English has a wide range of reporting verbs, "it seems to be a conventional feature of English dialogues to use profusely the general verb to say, leaving to the reader the inference of the specific role that the utterance plays in the interaction frame." In contrast, in Spanish dialogues the persistent reiteration of decir ("to say") would be perceived as "a lack of stylistic naturalness, [therefore] translators prefer to look for variants, by incorporating to 
the verb information surrounding the communicative event" (Rojo \& Valenzuela, 2001: 476). Similarly, in the context of Czech translation, Levý (2011:113) explains that "most professional translators are aware [...] that the stereotypical repetition of said in English introducing direct speech quite simply belongs to a different literary convention and as a rule they vary the way they represent this reporting verb in translation." The same could be valid for the other target languages studied in the afore-mentioned papers: German and Hungarian narrative styles, too, may favour a wider variety of reporting verbs over the repetitive use of the same ones. It is not only the repetition of reporting verbs that is avoided in translation: other repeated patterns, such as clusters and keywords, have also been shown to be avoided by literary translators (Čermáková \& Fárová, 2010; Čermáková, 2015). Overall, avoiding repetition is generally seen as a must-do in translation, independently from the language pair (see Ben-Ari, 1998).

Either way, further research is needed to better describe and understand how such an important element of many literary texts is translated. This is particularly true in the context of Italian, for which there is - as far as I am aware - no investigation into the translation of reporting verbs. This paper seeks to redress this existing gap, contributing to the field with a study that, on the one hand, represents an initial investigation into the translation of English reporting verbs in Italian, and, on the other, contributes more generally to the study of reporting verbs in translation, with a focus on their role in the characterisation process. The data, together with the methods used, is described in the next section.

\section{Data and methods}

This study investigates reporting verbs in the Harry Potter novels and their translation into Italian, focusing on the verbs attributed to the three protagonists of the series: Harry Potter, Ron Weasley, and Hermione Granger. This series is an ideal case study for an investigation like this. It is composed of seven books (totalling $1,080,041$ words) all sharing the same three protagonists. It therefore provides a considerable number of reporting verbs for the same characters, more than what the existing literature on reporting verbs and characterisation has analysed (see below). Moreover, each novel in the series covers one school year of the protagonists, following them from when they are 11 years old to when they are 17 . As such, the series lends itself quite well to study characterisation as a developing element, rather than a static feature. The STs and TTs are freely available for online searches on InterCorp (Čermák \& Rosen, 2012), a multilingual parallel corpus developed in the context of the Czech National Corpus project (https:// www.korpus.cz/). The translations available in InterCorp are the first Italian edi- 
tions of the Harry Potter series, originally published by Salani Publishing House between 1998 and 2008. The books have been translated by two different translators: Marina Astrologo translated the first two novels and Beatrice Masini translated the other five. The presence of two translators is beneficial for this study, as it provides a chance to compare the practice of two professionals and check whether tendencies identified in the translation of reporting verbs are specific to one translator only or are shared between two different translators. Moreover, the division of the series in two parts based on the translator offers further possibilities for comparison. The first part, comprising books 1 and 2 translated by Astrologo, covers the first two years of Harry, Ron, and Hermione at the Hogwarts School of Magic; these books have a lighter tone and are addressed to a younger audience, and the protagonists are very young, too (11 and 12 years old). In the second part, comprising books 3, 4, 5, 6, and 7 translated by Masini, Harry, Ron, and Hermione grow up (from 13 to 17 years old) and this is reflected in a more mature tone and plot - even darker to some respect - better fitting an older audience. Hence, comparing the first to the second part would allow for a discussion of character development throughout the series as reflected by patterns of reporting verbs, as well as whether/to what extent different strategies in the translation of reporting verbs into Italian may have affected the characters' development (see Mastropierro, 2019).

The texts in the corpus are searchable via a web-based concordancer called KonText (Machálek, 2014), which allows CQL queries as well as the use of regular expressions. A combination of both was used to retrieve the reporting verbs from the originals, using the following query (for the verbs attributed to Harry):

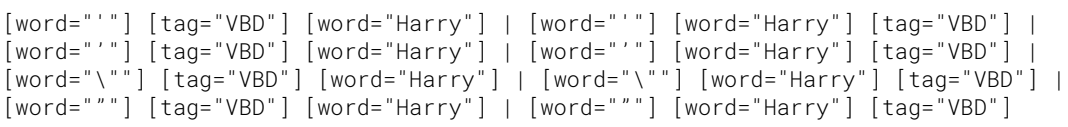

Basically, this query identified all instances of any type of closing quotation mark - as different types are used throughout the series - followed by the name of the character (Harry in this case), followed by a simple past verb; or any type of closing quotation mark, followed by a simple past verb, followed by the name of the character. This query does not capture instances where Harry, Ron, and Hermione are referred to with pronouns, but allows me to focus on the series' protagonists without having to identify manually the referent of each individual pronoun. Figure 1 shows a few lines of the resulting concordance.

As Figure 1 shows, this query retrieved a small amount of noise, represented by verbs occurring in the specified position that were not reporting verbs; this is the case of took in Figure 1. These verbs were manually removed. This procedure produced a total of 7,842 reporting verbs: 3,902 for Harry, 2,116 for Ron, and 


\begin{tabular}{|c|c|c|}
\hline of his hand .'You moron, Dudley! & ' Harry yelled & , his eyes watering with pain as he scrambled to \\
\hline YOU DO, KEEP YOUR MOUTH SHUT ! Wand! & 'Harry muttered & frantically, his hands flying over the ground like spiders \\
\hline away, bat-like and defeated.'THIS WAY! & 'Harry shouted & at the stag. Wheeling around, he sprinted down \\
\hline though about to kiss him .'GET IT! & 'Harry bellowed & , and with a rushing, roaring sound, the \\
\hline 'CHAPTER TWO A pack of Owls' what? & 'said Harry & blankly. ' He left!'said Mrs Figg \\
\hline ground, quick!"You know Dumbledore? & 'said Harry & , staring at her.' Of course I know \\
\hline Shut very light. 'I'Il do it. & 'Harry took & hold of Dudley's arm and heaved. With an \\
\hline tell me you're a squib, Mrs Figg? & ' asked Harry & , panting with the effort to keep walking \\
\hline
\end{tabular}

Figure 1. Concordance sample for reporting verbs attributed to Harry

1,824 for Hermione. Table 1 provides an overview of the data retrieved and shows how it has been divided into two main groups: the first including reporting verbs attributed to Harry, Ron, and Hermione in books 1 and 2 - those translated by Astrologo - and the second including reporting verbs attributed to Harry, Ron, and Hermione in books 3, 4, 5, 6, and 7, translated by Masini. The first group counts 1,092 reporting verbs, while the second counts 6,750 verbs. Moreover, each main group is further divided in three sub-groups, one per character, including all the reporting verbs attributed to each of them in books 1 and 2 and in books 3 , $4,5,6$, and 7. As mentioned at the beginning of this section, this organisation of the data allows me not only to compare the work of two different translators but also to track character changes from the first to the second part of the series, and assess the effect that the translation of reporting verbs may have had on it.

Table 1. Breakdown of the data per translator and character

\begin{tabular}{lllrrrr}
\hline \multirow{2}{*}{ Part } & \multirow{2}{*}{ Books } & Translators & \multicolumn{4}{c}{ Reporting verbs } \\
\cline { 4 - 6 } & & & Harry & Ron & Hermione & Total \\
\hline 1st & 1,2 & Astrologo & 522 & 420 & 150 & 1,092 \\
\multirow{2}{*}{ 2nd } & $3,4,5,6,7$ & Masini & 3,380 & 1,696 & 1,674 & 6,750 \\
\hline
\end{tabular}

Overall, this pool of data is considerably larger than what has been so far studied in the existing literature: for example, Rojo \& Valenzuela (2001) analyse 400 verbs, Bourne (2002) 100, Klaudy \& Károly (2005) 300, Winters (2007) 518, Yu \& Guo (2016) 120, Ruano San Segundo (2017a) 332, while Čermáková \& Mahlberg (2018) explore the translation of around 250 verbs. The only exception I am aware of is Corness (2010), who investigates the translation of around 10,000 reporting verbs, but he mainly adopts a quantitative perspective, employing 22 novels and therefore not discussing the effect of translation on the characterisation of any character or in any novel in particular. 
To retrieve the Italian verbs, the "Aligned corpora" function of KonText was used. This functionality allows the user to align automatically any ST with its available translations and search the texts via a parallel concordancer. English verb types were searched individually so that all of their Italian translations could be identified and recorded.

In order to provide a more nuanced understanding of how reporting verbs are translated into Italian, this study uses Caldas-Coulthard's (1987) taxonomy. This taxonomy groups reporting verbs into seven main categories: neutral verbs, structuring verbs, metapropositional verbs, metalinguistic verbs, prosodic verbs, paralinguistic verbs, and signalling discourse verbs. 'Neutral verbs' (e.g. say and tell) are those that "simply signal the illocutionary act - the saying" (CaldasCoulthard, 1987:153), without conveying any illocutionary force. 'Structuring verbs' (e.g. ask and reply) "describe the way in which a given speech act [...] fits into a sequence of speech acts" (Caldas-Coulthard, 1987:155), signalling prospection in the case of verbs like ask and inquire, and retrospection in the case of verbs like answer and reply. 'Metapropositional', or 'illocutionary verbs' are "highly interpretative" as, in addition to indicating the illocutionary act, they also elucidate "the author's [or, better, the narrator's] intended illocutionary force" (CaldasCoulthard, 1987:156). They can be 'assertive' (e.g. exclaim or declare), 'directive' (e.g. urge or instruct), or 'expressive' (e.g. complain or accuse). 'Metalinguistic verbs', such as narrate and quote, "refer to a linguistic act and not to a proposition" (Caldas-Coulthard, 1987: 161). 'Prosodic verbs' "present non-segmental characteristics of speech" and express "vocal effects constituted by variation of pitch, loudness, and duration" (Caldas-Coulthard, 1987:162); some examples are shout and cry. 'Paralinguistic verbs' are divided in two sub-categories based on phonetic differences: voice qualifiers (e.g. whisper and mutter) are employed "to mark manner" (Caldas-Coulthard, 1987:162, emphasis in the original), while 'voice qualification verbs' (e.g. laugh and sigh) "mark the attitude of the speaker in relation to what is being said" (Caldas-Coulthard, 1987:163, emphasis in the original) and, differently from all other descriptive verbs, cannot be used in indirect speech. Finally, 'signalling discourse verbs' are not, strictly speaking, reporting verbs. Rather, they "mark the interaction and [...] guide the reader through a simulated process" by either marking "the relationship of the quote to other parts of the discourse" (e.g. repeat and echo), or "mark the development of the discourse" (Caldas-Coulthard, 1987:163-164), such as pause or break in. A detailed description of the categories can be found in Caldas-Coulthard (1987), while Table 2 provides an overview of the taxonomy and some examples.

This taxonomy offers a more detailed classification of reporting verbs compared to what has been used in the existing literature (the opposition between general and specific verbs; c.f. Rojo \& Valenzuela, 2001; Klaudy \& Károly, 2005; 
Table 2. Reporting verb taxonomy (adapted from Caldas-Coulthard, 1987)

\begin{tabular}{lll}
\hline Category & Sub-category & Examples \\
\hline Neutral & & say, tell \\
Structuring & ask, inquire, reply, answer \\
Metapropositional & Assertive & urge, instruct, order
\end{tabular}

Yu \& Guo, 2016). This is particularly important when it comes to assessing the translation of a ST verb into a TT verb that is not its most obvious equivalent, as being able to compare differing categories can shed some light on the potential effect of the translation alteration.

The analysis comprises the following steps. First, a quantitative comparison of verb tokens and types is established between STs and TTs (Section 4). The investigation then zooms in on the top 10 most frequent verbs for each character, identifying differences and similarities in the way the speech of Harry, Ron, and Hermione is reported, both in English and Italian. This narrowed-down focus allows me to link the overall comparison of tokens and types to a discussion of characters, showing how divergences in the usage of reporting verbs between the STs and the TTs are reflected on the process of characterisation. Section 5 brings Caldas-Coulthard's (1987) taxonomy into the picture. Each individual verb is classified using Caldas-Coulthard's (1987) classification, and the frequency of verb categories is compared across languages. Statistically significant differences are identified between the STs and TTs, leading to the discussion of tendencies in the translation of reporting verbs from English into Italian. These differences are finally contextualised in two case studies (Section 6) that show, through a comparison of specific verb categories, how the tendencies discussed in Section 5 have the potential to impact the representation of Harry and his characterisation. 


\section{Reporting verbs comparison between STs and TTs}

The methods described in Section 3 retrieved 7,842 reporting verbs in the seven STs. These are divided in 122 types (different verbs), the first 10 of which account for $90 \%$ of the total occurrences. Said alone occurs 5,825 times ( $74 \%$ of the total), while only 10 other verbs account for $1 \%$ of the total or more (asked, $6 \%$; whispered, $2 \%$; muttered, $2 \%$; yelled, $1 \%$; shouted, $1 \%$; told, $1 \%$; repeated, $1 \%$; began, $1 \%$; gasped, $1 \%$; snapped, $1 \%$ ). The remaining 111 verbs occur 37 or fewer times, accounting for less than $1 \%$ each. A very similar picture emerges when checking frequencies in the two parts, with said accounting for $73 \%$ and $74 \%$ of the total in Part 1 and in Part 2 respectively, and the first 13 and 10 verb types in Part 1 and in Part 2 accounting for $90 \%$ of all occurrences respectively. This is in line with Rojo \& Valenzuela (2001:476), who suggest that "English dialogues use profusely the general verb to say", despite the fact that English has a wide range of more specific reporting verbs.

The same pattern identified in the whole of the data arises also when looking at the three characters individually. That is, the vast majority (90\%) of the verb tokens is represented by the repeated occurrence of a very small number of types (about 10); said in particular always accounts for around three quarters of the total number of verbs. In the case of Harry, in Part 1, 10 types account for $90 \%$ of all verb occurrences, with said accounting for $71 \%$ of them; in Part 2, eight types account for $90 \%$ of the total, with said accounting for $74 \%$. As for Ron, in Part 1 , $90 \%$ of the total occurrences are accounted by 11 types, while the frequency of said covers $75 \%$ of the total; in Part 2, eight types account for $90 \%$, with said covering $76 \%$ of the total. Finally, in the case of Hermione, in Part 1,10 types account for $90 \%$ of the total, with said accounting for $75 \%$; in Part 2, 90\% of all tokens is represented by nine types, while said accounts for $73 \%$. The consistency of this pattern across the data (whole dataset, Part 1 and Part 2, and individual characters) suggests that in the Harry Potter series the use of reporting verbs is dominated by repetition, whereas lexical variation represents only a small fraction of the total usage. Tables $3 \mathrm{a}$ and $3 \mathrm{~b}$ compare the 10 most frequent verbs for each character across the two parts, offering additional insights into this pattern.

As Tables $3 \mathrm{a}$ and $3 \mathrm{~b}$ show, most of the top frequent reporting verbs - those that account for between $89 \%$ and $93 \%$ of the total number of verbs - are shared across characters. In Part 1 , said, asked, whispered, and gasped are shared by all three characters; their frequencies account for $81 \%$ (Harry), $80 \%$ (Ron), and $81 \%$ (Hermione) of the total. In Part 2, the characters share said, asked, and whispered, accounting for $82 \%$ (Harry), $84 \%$ (Ron), and $84 \%$ (Hermione) of the total. In addition to these, another four verbs in Part 1 and seven in Part 2 are shared by two characters, especially Harry and Ron, increasing the homogeneity of verb 
Table 3a. Top 10 most frequent English verbs for each character in Part ${ }^{*}$

\begin{tabular}{|c|c|c|c|c|c|c|c|c|}
\hline \multicolumn{3}{|c|}{ Harry (Part 1) } & \multicolumn{3}{|c|}{ Ron (Part 1) } & \multicolumn{3}{|c|}{ Hermione (Part 1) } \\
\hline Verbs & $\%$ & Freq. & Verbs & $\%$ & Freq. & Verbs & $\%$ & Freq. \\
\hline said & $71 \%$ & 372 & said & $75 \%$ & 315 & said & $75 \%$ & 113 \\
\hline asked & $5 \%$ & 28 & muttered & $3 \%$ & 14 & asked & $2 \%$ & 3 \\
\hline muttered & $3 \%$ & 15 & whispered & $2 \%$ & 10 & gasped & $2 \%$ & 3 \\
\hline whispered & $2 \%$ & 13 & asked & $2 \%$ & 7 & snapped & $2 \%$ & 3 \\
\hline yelled & $2 \%$ & 8 & snapped & $1 \%$ & 5 & whispered & $2 \%$ & 3 \\
\hline gasped & $2 \%$ & 8 & $\underline{\text { told }}$ & $1 \%$ & 5 & continued & $1 \%$ & 2 \\
\hline told & $1 \%$ & 7 & yelled & $1 \%$ & 5 & cried & $1 \%$ & 2 \\
\hline called & $1 \%$ & 6 & gasped & $1 \%$ & 4 & shrieked & $1 \%$ & 2 \\
\hline hissed & $1 \%$ & 6 & moaned & $1 \%$ & 4 & squeaked & $1 \%$ & 2 \\
\hline croaked & $1 \%$ & 5 & sighed & $1 \%$ & 4 & squealed & $1 \%$ & 2 \\
\hline
\end{tabular}

* Bold for verbs shared by all three characters, underlined for verbs shared by two characters (within the top 10).

Table 3b. Top 10 most frequent English verbs for each character in Part 2 *

\begin{tabular}{|c|c|c|c|c|c|c|c|c|}
\hline \multicolumn{3}{|c|}{ Harry (Part 2) } & \multicolumn{3}{|c|}{ Ron (Part 2) } & \multicolumn{3}{|c|}{ Hermione (Part 2) } \\
\hline Verbs & $\%$ & Freq. & Verbs & $\%$ & Freq. & Verbs & $\%$ & Freq. \\
\hline said & $74 \%$ & 2,503 & said & $76 \%$ & 1,294 & said & $73 \%$ & 1,228 \\
\hline asked & $8 \%$ & 254 & asked & $6 \%$ & 103 & whispered & $6 \%$ & 93 \\
\hline muttered & $2 \%$ & 70 & muttered & $2 \%$ & 32 & asked & $5 \%$ & 82 \\
\hline yelled & $2 \%$ & 66 & yelled & $1 \%$ & 24 & cried & $2 \%$ & 27 \\
\hline shouted & $2 \%$ & 56 & shouted & $1 \%$ & 23 & snapped & $1 \%$ & 21 \\
\hline repeated & $1 \%$ & 42 & whispered & $1 \%$ & 21 & gasped & $1 \%$ & 19 \\
\hline told & $1 \%$ & 36 & demanded & $1 \%$ & 15 & screamed & $1 \%$ & 17 \\
\hline began & $1 \%$ & 30 & told & $1 \%$ & 14 & $\underline{\text { began }}$ & $1 \%$ & 15 \\
\hline whispered & $1 \%$ & 28 & bellowed & $1 \%$ & 11 & squealed & $1 \%$ & 10 \\
\hline bellowed & $1 \%$ & 23 & repeated & $1 \%$ & 11 & breathed & $1 \%$ & 9 \\
\hline
\end{tabular}

* Bold for verbs shared by all three characters, underlined for verbs shared by two characters (within the top 10).

usage. Just 17 of the 60 top-frequency verbs are unique to a single character, this character often being Hermione (11 unique verbs), whose reporting verb profile is characterised by verbs defining high-pitch effects. These, nevertheless, represent 
a fraction of the total. More generally, the similarities among the main characters support the overall uniformity of reporting verbs in the series, defined by the repetition of the same few verbs multiple times: in the vast majorities of cases, the same verbs are used for Harry, Ron, and Hermione.

It is only small sets of verbs that are specific to individual characters and distinguish their manner of speech from each other. In total, there are 11 and 19 reporting verbs unique to Harry in Part 1 and Part 2 respectively, compared to Ron and Hermione, occurring 18 and 32 times; that is, they account for $3 \%$ and less than $1 \%$ of the total number of verbs related to Harry. Ron has 16 unique verbs in Part 1 and 16 in Part 2, compared to the other two characters, occurring in total $26(6 \%)$ and 20 times (1\%), respectively. Finally, the reporting verbs unique to Hermione, in contrast with the two boys, are seven in Part 1 and 17 in Part 2, occurring in total $11(7 \%)$ and $72(4 \%)$ times respectively. Lack of space prevents me from discussing all unique verbs for each character, but the case of Hermione will suffice to suggest that these small, but distinctive, sets of verbs can play a major role in the characterisation process, as they contribute most to make one character uniquely different from the others. The reporting verbs unique to Hermione, shown in Table 4, are highly idiosyncratic, despite the fact that they individually occur only a few times (on average 3.5 times each). These verbs uniquely represent Hermione as the character who produces high-pitched voice effects: shrieked, squeaked, squealed, screamed, cried, wailed, whimpered, sobbed, cooed, screeched, wheezed. Eberhardt (2017), who identifies similar verbs in relation to Hermione, interprets the uniqueness of this group of reporting verbs as a reflection of a gendered representation, as they evoke "stereotypes of normative femininity" insomuch as they suggest elements of squimishness, fearfulness, and helplessness in Hermione's character (Eberhardt, 2017: 235).

Table 4. Hermione's unique verbs in English

\begin{tabular}{lcclc}
\hline & Part 1 & & & \multicolumn{2}{c}{ Part 2 } \\
\cline { 1 - 2 } \cline { 5 - 5 } Verbs & Freq. & & Verbs & Freq. \\
\hline shrieked & 2 & & cried & 27 \\
squeaked & 2 & & squealed & 10 \\
squealed & 2 & & shrieked & 8 \\
continued & 2 & & squeaked & 6 \\
ordered & 1 & & wailed & 4 \\
wheedled & 1 & & whimpered & 3 \\
screamed & 1 & & pleaded & 2
\end{tabular}


Table 4. (continued)

\begin{tabular}{|c|c|c|c|}
\hline \multicolumn{2}{|c|}{ Part 1} & \multicolumn{2}{|c|}{ Part 2} \\
\hline Verbs & Freq. & Verbs & Freq. \\
\hline & & sobbed & 2 \\
\hline & & insisted & 1 \\
\hline & & stormed & 1 \\
\hline & & cooed & 1 \\
\hline & & gulped & 1 \\
\hline & & screeched & 1 \\
\hline & & wheezed & 1 \\
\hline & & intoned & 1 \\
\hline & & read & 1 \\
\hline
\end{tabular}

In Italian, the picture is quite different. In the whole series, disse (the Italian equivalent of said) accounts for only $29 \%$ of the total $(2,242)$, and 46 verb types are needed to account for $90 \%$ of all occurrences, compared to 10-13 in English. This is a reflection of the overall greater variety of verbs employed in the TTs: 249 different verbs compared to the 122 in English. When looking at the individual translators, the overall tendency is the same, but some differences can be noted. In both parts, disse occurs considerably less than said in the ST equivalent parts ( $42 \%$ vs. $73 \%$ in Part 1 and $26 \%$ vs. $74 \%$ in Part 2), although Masini uses it proportionally more frequently than Astrologo (42\% vs. $26 \%$ ). Similarly, 33 verb types in Part 1 account for $90 \%$ of the total (compared to 13 in English), and 45 in Part 2 (compared to 10 in English). An equivalent pattern - and difference between translators - is found when looking at characters individually, as can be seen in Tables $5 \mathrm{a}$ and $5 \mathrm{~b}$, which provide a breakdown of these comparisons.

Table 5a. Frequency of disse and said as a \% of the total number of reporting verbs in Italian and English

\begin{tabular}{lcclcc}
\hline & \multicolumn{2}{c}{ Disse } & & \multicolumn{2}{c}{ Said } \\
\cline { 2 - 3 } \cline { 5 - 6 } & Part 1 & Part 2 & & Part 1 & Part 2 \\
\hline Series & $42 \%$ & $26 \%$ & & $73 \%$ & $74 \%$ \\
Harry & $37 \%$ & $24 \%$ & & $71 \%$ & $74 \%$ \\
Ron & $47 \%$ & $33 \%$ & & $75 \%$ & $76 \%$ \\
Hermione & $43 \%$ & $26 \%$ & & $75 \%$ & $73 \%$ \\
\hline
\end{tabular}


Table 5 b. Number of verb types accounting for $90 \%$ of all occurrences of reporting verbs in Italian and English

\begin{tabular}{lcccccc}
\hline & \multicolumn{2}{c}{ ITA } & & \multicolumn{2}{c}{ ENG } \\
\cline { 2 - 3 } \cline { 5 - 6 } & Part 1 & Part 2 & & Part 1 & Part 2 \\
\hline Series & 33 & 45 & & 13 & 10 \\
Harry & 26 & 51 & & 10 & 8 \\
Ron & 30 & 41 & & 11 & 8 \\
Hermione & 27 & 42 & & 10 & 9 \\
\hline
\end{tabular}

Overall, this suggests that the TTs are characterised by a much wider lexical variety, as far as reporting verbs are concerned: not only the English verbs are translated into a larger number of different verb types, but more verbs are used more often, with all three main characters. Even though this greater lexical variety aligns with what has been found in other studies on the translation of reporting verbs from English into other languages (see the discussion of Rojo \& Valenzuela, 2001; Bourne, 2002; Klaudy \& Károly, 2005; Winters, 2007; and Corness, 2010, in Section 2), the scale of this variety in the Italian translation of the Harry Potter series is quite striking. For example, whereas Rojo \& Valenzuela (2001) find that the 50 English verbs they analyse are translated into 60 different Spanish verb types, in my data there is about twice the number of different verb types in TTs compared to the STs (249 vs. 122), and this is also valid for both parts (110 vs. 64 in Part 1, 226 vs. 114 in Part 2), indicating that this tendency is not restricted to one translator only. Said alone, that in the STs accounts for $74 \%$ of all occurrences, has been translated in 207 different ways in the TTs. Tables $6 \mathrm{a}$ and $6 \mathrm{~b}$ compare the top 10 verbs in Italian per characters, furthering the understanding of the differences between the STs and the TTs.

On the one hand, Tables $6 \mathrm{a}$ and $6 \mathrm{~b}$ show an even greater degree of homogeneity between characters. There is very little variation in the reporting verbs most frequently used with Harry, Ron, and Hermione, especially in Part 1, while in Part 2, Ron is the character who stands out as the one with the largest number of most frequent unique verbs. On the other hand, the shared verbs account for a smaller portion of the total compared to what is seen in English. This is especially true in Part 2, where the percentage of top-frequency reporting verbs shared by all three characters averages $56 \%$ of the total, compared to an average of $83 \%$ in English. This signals a larger variety in the number of verb types used per character in Italian, a result of the fact that, in many cases and especially with said, English reporting verbs have not been translated with their most immediate equivalent in Italian (e.g. disse, in the case of said). The impact of this strategy, used by both 
Table 6a. Top 10 most frequent Italian verbs for each character in Part $1{ }^{*}$

\begin{tabular}{|c|c|c|c|c|c|c|c|c|}
\hline \multicolumn{3}{|c|}{ Harry (Part 1) } & \multicolumn{3}{|c|}{ Ron (Part 1) } & \multicolumn{3}{|c|}{ Hermione (Part 1) } \\
\hline Verbs & $\%$ & Freq. & Verbs & $\%$ & Freq. & Verbs & $\%$ & Freq. \\
\hline disse & $37 \%$ & 194 & disse & $47 \%$ & 196 & disse & $43 \%$ & 65 \\
\hline chiese & $17 \%$ & 87 & chiese & $12 \%$ & 51 & chiese & $9 \%$ & 14 \\
\hline rispose & $8 \%$ & 43 & esclamò & $5 \%$ & 23 & rispose & $5 \%$ & 8 \\
\hline gridò & $4 \%$ & 19 & $\underline{\text { commentò }}$ & $3 \%$ & 14 & $\underline{\text { commentò }}$ & $3 \%$ & 5 \\
\hline esclamò & $3 \%$ & 16 & fece & $2 \%$ & 10 & esclamò & $3 \%$ & 5 \\
\hline fece & $3 \%$ & 14 & gridò & $2 \%$ & 10 & gridò & $3 \%$ & 5 \\
\hline sussurrò & $2 \%$ & 13 & rispose & $2 \%$ & 8 & fece & $3 \%$ & 4 \\
\hline bisbigliò & $2 \%$ & 12 & bofonchiò & $2 \%$ & 7 & rimbeccò & $3 \%$ & 4 \\
\hline dire & $2 \%$ & 8 & bisbigliò & $1 \%$ & 6 & $\underline{\text { sbottò }}$ & $2 \%$ & 3 \\
\hline ripeté & $2 \%$ & 8 & $\underline{\text { sbottò }}$ & $1 \%$ & 5 & bisbigliò & $1 \%$ & 2 \\
\hline
\end{tabular}

* Bold for verbs shared by all three characters, underlined for verbs shared by two characters (within the top 10).

Table 6 b. Top 10 most frequent Italian verbs for each character in Part 2 *

\begin{tabular}{|c|c|c|c|c|c|c|c|c|}
\hline \multicolumn{3}{|c|}{ Harry (Part 2) } & \multicolumn{3}{|c|}{ Ron (Part 2) } & \multicolumn{3}{|c|}{ Hermione (Part 2) } \\
\hline Verbs & $\%$ & Freq. & Verbs & $\%$ & Freq. & Verbs & $\%$ & Freq. \\
\hline disse & $24 \%$ & 801 & disse & $33 \%$ & 555 & disse & $26 \%$ & 431 \\
\hline rispose & $15 \%$ & 502 & chiese & $12 \%$ & 210 & rispose & $10 \%$ & 162 \\
\hline chiese & $13 \%$ & 430 & rispose & $7 \%$ & 111 & chiese & $8 \%$ & 137 \\
\hline esclamò & $3 \%$ & 118 & esclamò & $4 \%$ & 73 & esclamò & $6 \%$ & 97 \\
\hline ribatté & $3 \%$ & 106 & commentò & $3 \%$ & 48 & sussurrò & $5 \%$ & 91 \\
\hline urlò & $3 \%$ & 102 & ribatté & $2 \%$ & 40 & ribatté & $3 \%$ & 52 \\
\hline mormorò & $2 \%$ & 79 & borbottò & $2 \%$ & 35 & intervenne & $2 \%$ & 41 \\
\hline ripeté & $2 \%$ & 74 & fece & $2 \%$ & 32 & mormorò & $2 \%$ & 34 \\
\hline gridò & $2 \%$ & 56 & domandò & $2 \%$ & 30 & gridò & $2 \%$ & 30 \\
\hline replicò & $2 \%$ & 51 & osservò & $2 \%$ & 28 & sbottò & $2 \%$ & 28 \\
\hline
\end{tabular}

* Bold for verbs shared by all three characters, underlined for verbs shared by two characters (within the top 10).

translators, can be seen in the very different set of unique verbs attributed to Hermione. 
Table 7. Hermione's unique verbs in Italian

\begin{tabular}{|c|c|c|c|}
\hline \multicolumn{2}{|c|}{ Part 1} & \multicolumn{2}{|c|}{ Part 2} \\
\hline Verbs & Freq. & Verbs & Freq. \\
\hline strillò & 3 & s'indignò & 11 \\
\hline adulò & 1 & squittì & 11 \\
\hline blandì & 1 & singhiozzò & 3 \\
\hline obiettò & 1 & acconsentì & 2 \\
\hline ordinò & 1 & confessò & 2 \\
\hline redarguì & 1 & piagnucolò & 2 \\
\hline squittì & 1 & $z i t t i ̀$ & 2 \\
\hline \multirow[t]{18}{*}{ continuò } & 1 & fece eco & 1 \\
\hline & & blandì & 1 \\
\hline & & buttò lì & 1 \\
\hline & & consolò & 1 \\
\hline & & declamò & 1 \\
\hline & & informò & 1 \\
\hline & & ragionò & 1 \\
\hline & & rallegrò & 1 \\
\hline & & riattaccò & 1 \\
\hline & & rimarcò & 1 \\
\hline & & rimbottò & 1 \\
\hline & & rivelò & 1 \\
\hline & & rincarò & 1 \\
\hline & & gongolò & 1 \\
\hline & & pigolò & 1 \\
\hline & & precedette & 1 \\
\hline & & saltò & 1 \\
\hline & & lesse & 1 \\
\hline
\end{tabular}

Table 7 shows that the presence of high-pitch voice effect verbs is much less marked in Italian. There are only a few verbs that could fit into this group (strillo "screamed", squittì "squeaked", singhiozzò "sobbed", piagnucolò "whimpered", pigolo "cheeped"), occurring in total 21 times, compared to the 70 occurrences of the same group in English. This is a consequence of the tendency to increase the level of verb variety by translating the same verb type into multiple TT verbs. Specifically, many of Hermione's unique verbs have been translated into multiple different verbs, some of which are used in relation to Ron and Harry, too. For example, squeaked has been translated into squittì ("squeaked") but 
also strillò ("screamed"), gemette ("wailed"), and balbettò ("stuttered"); cried into strillò ("screamed"), but also gridò ("yelled"), esclamò ("exclaimed"), urlò ("shouted"), gemette ("wailed"), sbottò ("snapped"), and abbaiò ("barked"); wailed into gemette ("wailed"), but also balbettò ("stuttered") and disse ("said"). At the same time, a verb like strillo, which in Italian means shouting in a high-pitch voice, is used with Harry and Ron as one of the different translations of yelled, bellowed, and shouted, preventing it from being Hermione-specific. Overall, the increase of the number of verb types for each character means that there is more overlap between characters and there are fewer unique verbs. As a consequence, this impacts on the potential of the translated reporting verbs to reproduce the same characterising traits conveyed by the verbs in the original.

\section{Category comparison between STs and TTs}

The previous section established that the use of reporting verbs in the STs is dominated by the frequent repetition of a very small number of verbs. In contrast, the TTs present a much wider lexical variety when it comes to reporting verbs, as a result of translating the same ST items in multiple ways. To understand further how and what types of reporting verbs change from the source into the TTs, and to identify general patterns in these changes, in this section I compare frequencies across Caldas-Coulthard's (1987) categories. Table 8 shows a breakdown of frequency and percentage for each category in Caldas-Coulthard's (1987) taxonomy, both for the English and Italian texts. The symbol $\varnothing$ indicates verbs that have been removed and have not been translated in the TTs (zero translation). The whole list of verbs and their categories is provided in the Appendices.

Table 8. Reporting verb categories in the STs and TTs

\begin{tabular}{|c|c|c|c|c|c|c|}
\hline & \multicolumn{3}{|c|}{ STs } & \multicolumn{3}{|c|}{ TTs } \\
\hline & Freq. & Types & $\%$ & Freq. & Types & $\%$ \\
\hline Neutral & 5,897 & 3 & $75 \%$ & 2,382 & 7 & $30 \%$ \\
\hline Structuring & 480 & 3 & $6 \%$ & 1,973 & 15 & $25 \%$ \\
\hline Metapropositional & 324 & 50 & $4 \%$ & 1,667 & 140 & $21 \%$ \\
\hline Metalingustic & 6 & 4 & o\% & 8 & 6 & $0 \%$ \\
\hline Prosodic & 296 & 10 & $4 \%$ & 345 & 8 & $4 \%$ \\
\hline Voice qualifier & 359 & 6 & $5 \%$ & 383 & 9 & $5 \%$ \\
\hline Voice qualification & 298 & 33 & $4 \%$ & 292 & 36 & $4 \%$ \\
\hline Signalling discourse & 182 & 13 & $2 \%$ & 594 & 28 & $8 \%$ \\
\hline$\varnothing$ & / & / & / & 198 & / & $3 \%$ \\
\hline Total & 7,842 & 122 & $100 \%$ & 7,842 & 249 & $100 \%$ \\
\hline
\end{tabular}


As expected, in English, neutral verbs cover three quarters of all verb types, followed by paralinguistic verbs (voice qualifier and qualification, 9\%), and structuring verbs $(6 \%)$. In the TTs, neutral verbs make up a considerably smaller proportion of the total (30\%); compared to the STs, this difference in frequency is statistically significant ( $\mathrm{LL}=1540.78, p<0.0001)$. This suggests that English neutral verbs are translated into other types of verbs in Italian. These are structuring and metapropositional, whose frequency increases from $6 \%$ and $4 \%$ to $25 \%$ and $21 \%$ respectively (structuring: $L L=975.62, \quad p<0.0001$; metapropositional: $\mathrm{LL}=991.42, p<0.0001)$. This is a significant alteration that can affect considerably the function of the verb. Whereas a neutral verb (e.g. said) is "interpretatively empty" (Ruano San Segundo, 2017b:111), as it only signals an illocutionary act, structuring and propositional verbs are not. Structuring verbs like asked and replied have interactional implications, as they more markedly indicate an interaction between two or more speakers, an exchange structure in Caldas-Coulthard's (1987: 155) words. Metapropositional verbs are "highly interpretative", as not only they signal a linguistic act, but also "label and categorize the [...] contribution of a fictional speaker" (Caldas-Coulthard, 1987:156-157). A shift from a neutral to a structuring or a metapropositional verb can therefore have important stylistic and interpretative implications, as shown in Examples (3) and (4) below.

(3) ENG: 'But he's gone", said Uncle Vernon impatiently, without the slightest sign that the murder of Harry's parents might be a painful topic. 'That giant bloke said so. He's gone.' 'He's back,' said Harry heavily.

[Harry Potter and the Order of Phoenix]

ITA: «Ma è sparito» disse zio Vernon impaziente, senza minimamente pensare che l'assassinio dei genitori di Harry potesse essere un argomento penoso. «L'ha detto quel tipo gigante. È sparito». «È tornato» rispose Harry gravemente.

("But he's gone", said Uncle Vernon impatiently, without thinking at all that the murder of Harry's parents could be a painful topic. "That giant bloke said so. He’s gone.' "He's back" replied Harry gravely.)

(4) ENG: She turned to Harry. "You - you don't think you've still got your Trace on you, do you, Harry?" "He can't have," said Ron.

[Harry Potter and the Deathly Hallows] ITA: Si rivolse a Harry. «Tu... tu non credi di avere ancora addosso la Traccia, vero, Harry?» «Impossibile» decretò Ron.

(She turned to Harry. "You... You don't think you've still got the Trace on you, do you, Harry?" "Impossible" decreed Ron.)

In Example (3), said is translated with rispose ("replied"). The shift from a neutral to a structuring verb emphasises the interactive nature of the exchange and 
stresses Harry's active role in it. This role is particularly relevant in the context of this example, as Harry is talking about the return of Lord Voldemort, the main villain of the series, to his uncle. Uncle Vernon, throughout the novels, tries to deny the existence of the magical world to the point of ignoring the obvious. Therefore, by translating said with replied, the TT turns Harry's neutral and almost resigned speech into a more involved response that sounds almost like a challenge to what Uncle Vernon said. In Example (4), a metapropositional verb, decretò ("decreed"), is used to translate the neutral verb said. As a result, Ron's statement comes across as much more certain and forceful than in the original, a change that is reflected upon the character himself, who appears much more assertive than his English counterpart does in this instance.

The other verb category that increases significantly in the shift from the source to the TTs is that of signalling discourse verbs, although the increase is less marked than what was seen with structuring and metapropositional verbs. Signalling discourse verbs go from $2 \%$ in the STs to $8 \%$ in the TTs $(L L=230.39$, $p<0.0001$ ). These verbs convey "liveliness" in the interaction (Caldas-Coulthard, 1987:164), as they mark how a dialogue develops (e.g. paused, pursued) or refers to other parts of the discourse (e.g. added, repeated). They may not be as characterising as metapropositional verbs, but "hesitation, pauses, silences or interruptions can [nevertheless] encode attitudinal stances" (Ruano San Segundo, 2017b:112). Again, it is mostly the translation of neutral verbs into signalling discourse verbs that explains the increase in the occurrence of the latter category in the TTs, as shown in Example (5).

(5) ENG: "Just like Moody and Hagrid! So listen to them!" "No one's tried to attack me all year," said Harry. "No one's done anything to me at all -" "Except put your name in the Goblet of Fire," said Hermione.

[Harry Potter and the Goblet of Fire]

ITA: 'Come Moody e Hagrid! Quindi dai loro retta!' 'Nessuno cerca di aggredirmi' ribatté Harry. 'Nessuno mi ha fatto niente...' 'Tranne mettere il tuo nome nel Calice di Fuoco' lo interruppe Hermione.

("Like Moody and Hagrid! So listen to them!" "No one's tried to attack me," retorted Harry. "No one's done anything to me..." "Except put your name in the Goblet of Fire," interrupted Hermione.)

In Example (5), the neutral verb said is translated into the signalling discourse verb interruppe ("interrupted"). Compared to said, interruppe emphasises Hermione's disagreement with Harry and the vehemence with which it is conveyed. Together with the replacement of said with ribatté ("retorted") to gloss Harry's turn, interruppe makes this exchange more confrontational than its original version. 
When checking how the individual translators translated reporting verbs in Part 1 and Part 2, the same picture emerges. As seen in Tables 9a and 9b, which compare verb categories in both parts, frequencies of neutral verbs decrease in the translations, while structuring, metapropositional, and signalling discourse verbs occur significantly more frequently.

Table 9a. Reporting verb categories in the STs and TTs, Part 1

\begin{tabular}{|c|c|c|c|c|c|}
\hline & \multicolumn{2}{|c|}{ STs part 1} & \multicolumn{2}{|c|}{ TTs part 1} & \multirow[t]{2}{*}{ Statistical significance ${ }^{\star}$} \\
\hline & Freq. & $\%$ & Freq. & $\%$ & \\
\hline Neutral & 812 & $74 \%$ & 495 & $45 \%$ & $* * *$ \\
\hline Structuring & 38 & $3 \%$ & 221 & $20 \%$ & $\star * *$ \\
\hline Metapropositional & 68 & $6 \%$ & 186 & $17 \%$ & $* * *$ \\
\hline Metalinguistic & 2 & $0 \%$ & 2 & $0 \%$ & \\
\hline Prosodic & 30 & $3 \%$ & 39 & $4 \%$ & \\
\hline Voice qualifier & 68 & $6 \%$ & 58 & $5 \%$ & \\
\hline Voice qualification & 62 & $6 \%$ & 38 & $3 \%$ & \\
\hline Signalling discourse & 12 & $1 \%$ & 37 & $3 \%$ & ** \\
\hline$\varnothing$ & o & $0 \%$ & 16 & $1 \%$ & \\
\hline Total & 1,092 & $100 \%$ & 1,092 & $100 \%$ & \\
\hline
\end{tabular}

${ }^{\star * *} p<0.0001,{ }^{* *} p<0.001$

Table 9 b. Reporting verb categories in the STs and TTs, Part 2

\begin{tabular}{|c|c|c|c|c|c|}
\hline & \multicolumn{2}{|c|}{ STs part 2} & \multicolumn{2}{|c|}{ TTs part 2} & \multirow[t]{2}{*}{ Statistical significance ${ }^{*}$} \\
\hline & Freq. & $\%$ & Freq. & $\%$ & \\
\hline Neutral & 5,085 & $75 \%$ & 1,887 & $28 \%$ & $* * *$ \\
\hline Structuring & 442 & $7 \%$ & 1,752 & $26 \%$ & $\star * *$ \\
\hline Metapropositional & 256 & $4 \%$ & 1,481 & $22 \%$ & $* * *$ \\
\hline Metalinguistic & 4 & ०\% & 6 & $0 \%$ & \\
\hline Prosodic & 266 & $4 \%$ & 306 & $5 \%$ & \\
\hline Voice qualifier & 291 & $4 \%$ & 325 & $5 \%$ & \\
\hline Voice qualification & 236 & $3 \%$ & 254 & $4 \%$ & \\
\hline Signalling discourse & 170 & $3 \%$ & 557 & $8 \%$ & $* * *$ \\
\hline$\varnothing$ & o & $0 \%$ & 182 & $3 \%$ & \\
\hline Total & 6,750 & $100 \%$ & 6,750 & $100 \%$ & \\
\hline
\end{tabular}

$\star \star * * p<0.0001$ 
This suggests that the tendency to translate neutral verbs into structuring, metapropositional, and signalling discourse verbs is more than an idiosyncratic strategy of one translator only, as it is seen consistently across the work of both translators. There are, however, some differences between Astrologo and Masini. In line with the findings reported in Section 4, Astrologo, the translator of Part 1, uses neutral verbs more frequently than Masini, the translator of Part 2. Neutral verbs account for $45 \%$ of the total number of reporting verbs in Astrologo's TTs, while they account for $28 \%$ in Masini's TTs. Consequently, the increase in frequency of structuring, matapropositional, and signalling discourse verbs is smaller in Astrologo's translations, compared to Masini's; this may imply that the potential stylistic and characterising implications of changing reporting verb categories are relatively less marked in Astrologo's TTs compared to Masini's. Nevertheless, these divergences between the translators do not detract from the fact that, in both parts, statistically significant differences in frequency occur for the exact same verb categories.

\section{Potential effects on character development}

Both translators of the Harry Potter books in Italian toned down the repetition of reporting verbs in favour of lexical variation. More specifically, the repetition of neutral verbs (said in particular), which in the STs account for $75 \%$ of the total number of verbs, is mitigated by replacing neutral verbs with structuring, metapropositional, and signalling discourse verbs. In the previous section, I argued that these alterations can have stylistic implications and affect the characterisation process. In this section, I will discuss two brief case studies to demonstrate the potential effect of the change of verb category on the development of characters. Both examples focus on Harry, as this is the character for whom the largest number of reporting verbs was retrieved.

The first case study is concerned with the relation between prosodic and voice qualifier verbs. As explained in Section 3, prosodic verbs are descriptive verbs representing "vocal effects constituted by variation of pitch, loudness, and duration" (Caldas-Coulthard, 1987:162), typical examples of which are scream, cry, yell, and shout. Voice qualifiers are a sub-category of paralinguistic verbs resulting from "physiological mechanisms other than the vocal cords" (Crystal, 1969: 128, cited in Caldas-Coulthard, 1987:162) and are used "to mark manner" (Caldas-Coulthard, 1987:162, emphasis in the original); whisper, murmur, and mutter are representatives of this sub-category. Both prosodic and voice qualifiers are highly descriptive reporting verbs that define the manner of the utterance, although in a very different - almost opposite - way. In the STs, the balance between these categories 
changes between Part 1 and Part 2, reflecting the development of Harry as a character. Consider Table 10, which shows frequencies and percentage of each verb category for Harry.

Table 10. Reporting verb categories in the STs, Part 1 and Part 2 (Harry only)

\begin{tabular}{lccccc}
\hline & \multicolumn{2}{c}{ STs (Part 1) } & & \multicolumn{2}{c}{ STs (Part 2) } \\
\cline { 2 - 3 } \cline { 5 - 6 } & Freq. & $\mathbf{\%}$ & & Freq. & $\mathbf{\%}$ \\
\hline Neutral & 379 & $73 \%$ & & 2,541 & $75 \%$ \\
Structuring & 28 & $5 \%$ & & 254 & $8 \%$ \\
Metapropositional & 26 & $5 \%$ & & 117 & $3 \%$ \\
Metalinguistic & 1 & $0 \%$ & & 1 & $0 \%$ \\
Prosodic & 16 & $3 \%$ & & 151 & $4 \%$ \\
Voice qualifier & 37 & $7 \%$ & & 117 & $3 \%$ \\
Voice qualification & 27 & $5 \%$ & & 100 & $3 \%$ \\
Signalling discourse & 8 & $\mathbf{2} \%$ & & 99 & $3 \%$ \\
Total & $\mathbf{5 2 2}$ & $\mathbf{1 0 0} \%$ & & $\mathbf{3 , 3 8 0}$ & $\mathbf{1 0 0} \%$ \\
\hline
\end{tabular}

In Part 1, paralinguistic verbs, and voice qualifiers specifically (muttered, whispered, breathed, murmured, mouthed, mumbled) are used significantly more frequently ( $\mathrm{LL}=8.55, p<0.01$ ) than prosodic verbs (yelled, shouted, bellowed, cried). In fact, if we exclude neutral verbs, voice qualifiers are the most frequent category of reporting verbs. This means that in the first two books, Harry mutters and whispers more frequently than he yells and shouts. In Part 2, this difference is levelled out ( $L L=4.33, p>0.01$ ), as the frequency of prosodic verbs (yelled, shouted, bellowed, burst out, screamed, bawled, thundered) increases and that of voice qualifiers (muttered, whispered, mumbled, murmured) decreases. This indicates that in the following five books, Harry yells and shouts as frequently as he mutters and whispers. This change can be interpreted as a result of the development of Harry from Part 1 to Part 2. In the first two books, Harry is presented as a shy and introvert child, brought up in a family in which his voice is worth less than zero. At the beginning of the first novel, Harry is thrown into a world he knows nothing about - the world of wizards and witches. In the following books, Harry grows up into a more confident boy; at the same time, his role in the wizarding world becomes more and more central against his own will. We therefore see him arguing often with friends and teachers, and making his voice heard more explicitly and loudly, as a result of his struggles to understand and control what is happening around him. This development is reflected in the reporting verbs attributed to 
him, which turn Harry from a character who whispers a lot to one who yells as frequently.

The change of reporting verb categories in the TTs affects the balance between prosodic and voice qualifiers. In Part 1 , neutral and metapropositional verbs are at times translated into prosodic verbs, increasing the instances in which Harry shouts compared to the original. As a consequence, there is no significant difference between the frequency of prosodic verbs and that of voice qualifier verbs ( $L L=4.30, p>0.01)$ in Part 1 , and the contrast between Part 1 and Part 2 the latter being the one in which prosodic verbs increase - cannot be established. This difference in the reporting verbs attributed to Harry in the Italian translations has the potential to affect the development of the character throughout the series, turning Harry into a character who from the very beginning shouts as frequently as he whispers. Examples (6) and (7) show two instances of this shift:

(6) ENG: "Get out of the way, Colin!" said Harry angrily.

[Harry Potter and the Chamber of Secrets]

ITA: 'Fuori dai piedi, Colin!' gli gridò Harry infuriato.

(“Get out of the way, Colin!", shouted Harry at him furiously.)

(7) ENG: 'Give it here,' Harry called, 'or I'll knock you off that broom!'

[Harry Potter and the Philosopher's Stone]

ITA: 'Dammela' gli gridò Harry, 'o ti butto giù da quel tuo manico di scopa!'

("Give it here!" shouted Harry at him, "or I'll knock you off that broomstick of yours!”)

In Example (6), the neutral verb said is translated into the prosodic verb grido ("shouted"). It is probably the adverb angrily in the ST that triggered the choice of the prosodic verb in the TT, but said angrily and grido infuriato ("shouted furiously") gloss the utterance in very different ways, the latter conveying much more fervour and aggressiveness than the former. Similarly, the translation of the metapropositional verb called into the prosodic verb gridò ("shouted") in Example (7) depicts Harry as more forceful, loud, and hostile than his ST's counterpart.

The second case study focuses on structuring verbs and how their frequency increases throughout the original series to reflect changes in the way Harry interacts with people around him. In the STs, the frequency of structuring verbs those that indicate how an utterance "fits into a sequence of speech acts" (CaldasCoulthard, 1987:155), such as answer and ask - rise in Part 2. As Table 10 above shows, structuring verbs become the most frequent category of reporting verbs after neutral ones in Part 2, significantly more frequent than any other remaining verb category $(p<0.0001)$. However, structuring verbs do not have the same emphasis in Part 1, as in the first two books their frequency is not significantly different $(p>0.01)$ from the other major descriptive verb categories (metapropo- 
sitional, prosodic, voice qualifier, voice qualification). Considering that the category of structuring verbs in the STs is constituted by the verb asked only, it is safe to assume that in Part 2 Harry's questions are much more prominent than in Part 1. This, again, reflects the development of Harry as a character. Throughout the series, Harry becomes more confident and inquisitive, as well as more active in his attempts to understand and control his role and his fate in the magical world. The prominence of questions in Part 2 compared to Part 1 contributes to and mirrors this aspect of character development.

The pattern of structuring verbs identified in the original is altered in translation, because of the change of verb category that occurs in the TTs. As Section 5 showed, one of the major tendencies identified in the translation of reporting verbs is the replacement of neutral verbs with structuring verbs. Structuring verbs are already prominent in Part 1 , representing the most frequent category after neutral verbs, and stay prominent in Part 2, too, where they occur even more frequently than neutral verbs. As a result of this consistent prominent role throughout the novels, there is no shift from Part 1 to Part 2 that could highlight the development of Harry as a character who is more and more likely to ask questions as he gets older and more confident. Examples (8) and (9) show two instances in which neutral verbs in the STs have been replaced with structuring verbs in the TTs:

(8) ENG: 'Where's my letter?' said Harry, the moment Uncle Vernon had squeezed through the door. [Harry Potter and the Philosopher's Stone] ITA: 'Dovè la mia lettera?' chiese il ragazzo non appena zio Vernon fu riuscito a passare dallo sportello.

("Where's my letter?" asked the boy as soon as Uncle Vernon had managed to squeeze through the door.)

(9) ENG: 'MOTORBIKES DON'T FLY!' Dudley and Piers sniggered. 'I know they don't', said Harry. [Harry Potter and the Philosopher's Stone] ITA: LE MOTOCICLETTE NON VOLANO!' Dudley e Piers repressero una risata. 'Lo so che non volano' rispose Harry.

(“MOTORBIKES DON’T FLY!” Dudley and Piers repressed a laughter. “I know they don't fly" answered Harry.)

In Example (8), the neutral verb said is replaced by a structuring verb that signals prospection, chiese ("asked"), while in Example (9) said is translated into a verb that indicates retrospection, rispose ("answered"). In the majority of cases, neutral verbs are translated into structuring verbs signalling prospection like chiese ("asked") when the ST utterance is a question, as in Example (8). Technically speaking, then, Harry does ask a question. However, the use of chiese ("asked") foregrounds more the interactive nature of the utterance compared to said, 
emphasising Harry's active role in the exchange structure: whereas said indicates the act of producing an utterance, chiese ("asked") implies that the utterance is addressed to someone. Similarly, rispose ("answered") in Example (9) stresses more, compared to said, that Harry is addressing Dudley and Piers. Dudley is Harry's cousin who has bullied him throughout his childhood and keeps bullying Harry in the first few books of the series. The use of rispose ("answered") in the TT suggests more markedly that Harry is responding back to this cousin, compared to the more neutral said; this has the potential of slightly altering the perception of how the two speakers interact with each other. Admittedly, the differences described here are very subtle, but it is important to take into consideration that shifts like these occur repeatedly. In Part 1, said is translated with a structuring verb 109 out of 372 times (30\% of the total), while in Part 2 this shift occurs 789 out of 2,503 times ( $32 \%$ of the total). It is therefore a pattern of subtle changes, as those presented here and in the first case study, that can affect the characterisation process throughout the series, rather than the single choices of the translators on individual verbs. Bringing together a quantitative and qualitative perspective allowed me to identify general patterns first and then show the impact they can have on a more interpretative level.

\section{Conclusion}

This paper contributed to the study of reporting verbs in translation, providing new data on a previously unexplored translation direction: English to Italian. Not only did it offer a quantitative perspective with findings in line with the existing literature, but it also contributed novel insights that describe how reporting verbs are translated, identifying the most significant shifts in verb categories. Moreover, it demonstrated how these translation alterations can affect characters, emphasising the developmental nature of the characterisation process.

The translation of English reporting verbs in Italian follows the trend noticed in the translation of English reporting verbs in the other languages explored in previous research: the TTs employ a much larger number of verbs types compared to the STs, which are also used more frequently. The Italian texts favour lexical variety over repetition, especially in the case of said, which in English accounts for about three quarters of all verbs, while in Italian it is translated in 207 different ways. This strategy was shown to have the potential to influence the whole reporting verb profile of the characters, including the small, but highly distinctive, fraction of unique verbs that contributes most to distinguish characters from each other. More research is needed to confirm the extent to which this is a generalisable finding, but the fact that these tendencies are recognised in 
both translators seems to suggest that what the data shows is not just an idiosyncratic preference. More specifically, the increase in lexical variety in lieu of repetition is the result of three translational shifts: the replacement of neutral with structuring, metapropositional, and discourse signalling reporting verbs. These three categories become significantly larger in the Italian texts, while neutral verbs decrease. Given the stylistic differences between these verb categories, this paper suggested that these shifts can impact the development of the characters throughout the series, affecting the perception of how Harry, Ron, and Hermione interact with others and express themselves. This stresses once more the importance of studying reporting verbs in translation, and calls for more research that explores how this key characterisation device is - and maybe should be - translated.

In fact, although preliminary, the findings of this paper put into question the traditional view in translation pedagogy of repetition as an undesirable stylistic feature. In line with what Čermáková \& Fárová (2010) and Čermáková (2015) have shown in relation to the translation of other linguistic features, this study suggests that aiming to indiscriminately avoid repetition in translation could be detrimental, considering the functional and stylistic significance that repeated textual elements could have. Translators may not be aware of the existence of reiterated patterns in the ST, especially if they develop throughout multiple books, but should nevertheless recognise the intricate equilibrium that linguistic features establish in a text, and consider how the adherence to language conventions balances out against the reproduction of stylistic effects.

\section{References}

Baker, M. (1993). Corpus linguistics and translation studies - Implications and applications. In M. Baker, G. Francis, \& E. Tognini-Bonelli (Eds.), Text and Technology: In Honour of John Sinclair (pp. 233-250). John Benjamins. https://doi.org/10.1075/z.64.15bak

Ben-Ari, N. (1998). The ambivalent case of repetitions in literary translation. Avoiding repetitions: A 'universal' of translation. Meta, 43(1), 68-78. https://doi.org/10.7202/002054ar

Blum-Kulka, S. (2004). Shift of cohesion and coherence in translation. In L. Venuti (Ed.), Translation Studies Reader (2nd ed.) (pp. 290-305). Routledge.

Bourne, J. (2002). Controlling illocutionary force in the translation of literary dialogue. Target, 14(2), 241-261. https://doi.org/10.1075/target.14.2.04bou

Caldas-Coulthard, C. R. (1987). Reported speech in written narrative texts. In M. Coulthard (Ed.), Discussing Discourse (pp. 149-167). University of Birmingham.

Caldas-Coulthard, C.R. (1994). On reporting reporting: The representation of speech in factual and factional narratives. In M. Coulthard (Ed.), Advances in Written Text Analysis (pp. 295-308). Routledge. 
Čermák, F., \& Rosen, A. (2012). The case of InterCorp, a multilingual parallel corpus. International Journal of Corpus Linguistics, 17(3), 411-427. https://doi.org/10.1075/ijcl.17.3.05cer

Čermáková, A. (2015). Repetition in John Irving's novel a Widow for One Year. A corpus stylistic approach to literary translation. International Journal of Corpus Linguistics, 2o(3), 355-377. https://doi.org/10.1075/ijcl.20.3.04cer

Čermáková, A., \& Fárová, L. (2010). Keywords in Harry Potter and their Czech and Finnish translation equivalents. In F. Čermák, P. Corness, \& A. Klégr (Eds.), InterCorp: Exploring a Multilingual Corpus (pp. 177-188). NLN.

Čermáková, A., \& Mahlberg, M. (2018). Translating fictional characters - Alice and the Queen from the Wonderland in English and Czech. In A. Čermáková \& M. Mahlberg (Eds.), The Corpus Linguistics Discourse: In Honour of Wolfgang Teubert (pp. 223-253). John Benjamins. https://doi.org/10.1075/scl.87.10cer

Corness, P. (2010). Shifts in Czech translation of the reporting verb said in English fiction. In F. Čermák, P. Corness \& A. Klégr (Eds.), InterCorp: Exploring a Multilingual Corpus (pp. 159-176). NLN.

Culpeper, J. (2001). Language and Characterisation: People in Plays and Other Texts. Pearson Education.

Eberhardt, M. (2017). Gendered representations through speech: The case of the Harry Potter series. Language and Literature, 26(3), 227-246. https://doi.org/10.1177/0963947017701851

Klaudy, K., \& Károly, K. (2005). Implicitation in translation: Empirical evidence for operational asymmetry in translation. Across Languages and Cultures, 6(1), 13-28. https://doi.org/10.1556/Acr.6.2005.1.2

Laviosa, S. (2002). Corpus-based Translation Studies. Rodopi.

Leech, G., \& Short, M. (2007). Style in Fiction: A Linguistic Introduction to English Fictional Prose (2nd ed.). Pearson Longman.

Levý, J. (2011). The Art of Translation [transl. by P. Corness]. John Benjamins. https://doi.org/10.1075/btl.97

Machálek, T. (2014). KonText - Application for Working with Language Corpora [Computer software]. FF UK. Retrieved November, 2020, from http://kontext.korpus.cZ

Mastropierro, L. (2019, July 23-27). Reporting verbs in the Harry Potter series and its Italian translation: A corpus stylistic perspective [Paper presentation]. International Corpus Linguistics Conference 2019, Cardiff, UK.

Øverås, L. (1998). In search of the third code: An investigation of norms in literary translation. Meta, 43(4), 557-570. https://doi.org/10.7202/003775ar

Rojo, A., \& Valenzuela, J. (2001). How to say things with words: Ways of saying in English and Spanish. Meta, 46(3), 467-477. https://doi.org/10.7202/003971ar

Ruano San Segundo, P. (2016). A corpus-stylistic approach to Dickens' use of speech verbs: Beyond mere reporting. Language and Literature, 25(2), 113-129. https://doi.org/10.1177/0963947016631859

Ruano San Segundo, P. (2017a). Corpus methodologies in literary translation studies: An analysis of speech verbs in four Spanish translations of Hard Times. Meta, 62(1), 94-113. https://doi.org/10.7202/1040468ar

Ruano San Segundo, P. (2017b). Reporting verbs as a stylistic device in the creation of fictional personalities in literary texts. Journal of the Spanish Association of Anglo-American Studies, 39(2), 105-124. https://doi.org/10.28914/Atlantis-2017-39.2.06 
Ruano San Segundo, P. (2018a). An analysis of Charles Dickens's gender-based use of speech verbs. Gender \& Language, 12(2), 192-217. https://doi.org/10.1558/genl.31137

Ruano San Segundo, P. (2018b). Dickens's hyperbolic style revisited: Verbs that describe sounds made by animals used to report the words of male villains. Style, 52(4), 475-493.

Semino, E., \& Short, M. (2004). Corpus Stylistics: Speech, Writing and Thought Presentation in a Corpus of English Writing. Routledge. https://doi.org/10.4324/9780203494073

Simpson, P. (2004). Stylistics. A Resource Book for Students. Routledge. https://doi.org/10.4324/9780203496589

Toolan, M. (2001). Narrative. A Critical Linguistic Introduction (2nd ed.). Routledge.

Yu, H., \& Guo, S. (2016). The Master said, the Master exclaimed: Reporting verbs and the image of Huineng in translations of the Platform Sutra. Asia Pacific Translation and Intercultural Studies, 3(3), 267-279. https://doi.org/10.1080/23306343.2016.1228148

Winters, M. (2007). F. Scott Fitzgerald's Die Schönen und Verdammten: A corpus-based study of speech-act report verbs as a feature of translators' style. Meta, 52(3), 412-425. https://doi.org/10.7202/016728ar

\section{Appendices}

The appendices are available here: https://doi.org/10.1075/ijcl.19124.mas.additional

\section{Address for correspondence}

Lorenzo Mastropierro

School of English

University of Nottingham

Trent Building, University Park

Nottingham NG7 2RD

UK

lorenzo.mastropierro@nottingham.ac.uk 